\title{
An Analysis of the Current Situation of College Teachers' Incentive Mechanism and the Countermeasures
}

\author{
Liping Shi \\ School of Tianjin University of Finance and Economics, Tianjin 300222, China
}

Keywords: Colleges and Universities, Teachers, Incentive Mechanism.

\begin{abstract}
Being the main body of teaching and scientific research, teachers are the key force to promote the sustainable development of colleges and universities. It is of vital significance to perfect and optimize the teachers' incentive mechanism to promote their enthusiasm for work and professional development and improve efficiency in college management. This paper analyzes the present situation and the existing problems of the incentive mechanism for college teachers and puts forward the countermeasures and suggestions for improving and optimizing the incentive mechanism from three aspects: salary incentive, position competition and performance appraisal.
\end{abstract}

\section{Introduction}

Teachers serve as the important forces to promote the development of colleges and universities. How to cultivate their enthusiasm and initiative and tap their potentials is the key research direction of college management. Therefore, an effective teacher incentive mechanism must be established to promote the continuous improvement of college teachers' quality and the sustainable development of higher education.

First, the incentive mechanism for college teachers and its significance

Incentive mechanism belongs to the scope of management science, referring to the mechanism that according to certain laws and regulations, value orientation and cultural environment, the organization's managers provide material and spiritual motivation and encouragement for those being managed in terms of their behavior, idea and performance to make them continue to play their roles and bring positive benefits to their organizations. ${ }^{[1]}$ The so-called college teachers' incentive mechanism is a series of incentive measures for teachers adopted by the college in order to achieve established goals, and the purpose is to stimulate teachers' internal potential and enable them to improve performance and get acknowledgement and reward for their performance and work, and encourage them to continue to move towards desired goals. Scientific and reasonable incentive mechanism for college teachers can fully stimulate their enthusiasm for work and form a good college development cycle.

Second, the current situation of the incentive mechanism for college teachers

In recent years, China has explored and established relevant teachers' incentive mechanism, but still encountered many obstacles in exploring and practicing incentive mechanism and measures, mainly in the following aspects:

\section{Unreasonable Setting of Incentive Mechanism}

Complete, scientific and reasonable incentive mechanism is the important support for teachers to give full play to their roles. At present, the incentive mechanisms developed by many colleges and universities, such as reward standards and distribution, are not scientific, which makes them cannot fully play their roles. The reward standards are also set to be unscientific, resulting in one-size-fits-all situation; in terms of reward content, although most colleges and universities adopt economic reward as the main means of motivation, distributive equity isn't well achieved. Average distribution is often adopted without multiple comprehensive incentives and means. A reasonable incentive mechanism 
should be developed to ensure teachers fully realize their value so as to achieve the real effect of incentives.

\section{Uncompetitive and Unscientific Post Appointment}

In general, college teachers are appointed to corresponding posts according to their qualification and experience. The phenomenon of accepting only promotion but demotion is still widespread, leading to the lack of competition and development disconnect. At the same time, current teacher employment system lacks job analysis and classification management. Large heterogeneity exists in different disciplines and majors and teachers vary in their own ability and preferences, which requires colleges and universities to strengthen job analysis and adopt classified appointment and management according to different categories, disciplines and majors in their teacher appointment system. As a means of motivation, post appointment should be established on the basis of letting everybody fully display his talents so as to make sure everybody can give full play to his positive role.

\section{Problematic Performance Appraisal System}

The performance assessment of colleges and universities only focuses on quantitative indicators, not the qualitative indicators. In general, the performance appraisal system for college teachers mainly focuses on two aspects, that is, scientific research achievements and teaching quality. The publication of scientific research results, lessons and other indicators can be measured by quantitative method, but qualitative aspects like teaching content and teaching skills are difficult to assess. At the same time, the existing quantitative standards of scientific research are easy to encourage blind pursuit of quantity instead of high quality. Many teachers may pursue short-term behavior for their own interest and neglect teaching for a long time, unwilling or having no time to achieve the goal of cultivating talents.

\section{Lacking Inclusiveness and Flexibility in Salary Design}

At present, the salary level for college teachers is not competitive and balanced enough. According to the latest statistical results, the income level of college teachers only lies in the middle of various occupational incomes, far lower than that of foreign enterprises, monopoly industries and even civil servants. In the internal distribution, many colleges and universities attach great importance to the introduction of foreign talents and often provide them with generous remuneration; their pay incentives also significantly lay particular stress on high-level talents without enough attention to medium and low ranking teachers, resulting in extremely uneven income distribution. The salary incentive mode focuses on short-term incentive and the income distribution system lacks flexibility and richness.

Third, countermeasures and suggestions to improve and optimize the incentive mechanism for college teachers to improve and optimize the incentive mechanism for college teachers, we must take the concept of "people first" as the guide, fully understand and meet the legitimate needs of teachers, promote career development and achieve common development of the college and teachers through reasonable guidance of system and measure. To this end, the following countermeasures and suggestions are made:

\subsection{Establish and Improve Effective Salary Incentive Mechanism}

At present, college teachers, especially young and middle-aged teachers, bear heavy teaching and research tasks, but their salary is relatively low and many of them are dissatisfied with their salary and benefits. Adopting performance pay is the process of post reallocation and interest redistribution for the existing staff. It is the key for the college to establish performance pay allocation model to correctly handle and coordinate the performance pay level of teachers, administrative staff, ancillary staff and handymen. Therefore, colleges and universities must design different performance pay distribution models according to the nature and characteristics of different staff, and gradually establish an allocation incentive mechanism that is independent and flexible, stresses performance and contributions, gives priority to advanced talents and key posts, and take many forms. Of course, it is 
necessary to distinguish the legitimate interests of individuals and individualism while providing the material incentives and closely integrate material and spiritual incentives. [2]

\subsection{Introduce Competition Mechanism and Position Competition}

The adoption of position competition is the result of following the trend of the times. While setting posts, colleges and universities should focus on the discipline construction, the overall development of various undertakings, guiding and inspiring faculty continue to achieve innovation in work, performance and management, and the growth of teacher talents. They should implement the separation evaluation from appointment in professional title, scientifically set up post requirements and responsibilities, adopt competitive system of appointment based on the post, and develop fair and open competition rules, so as to mobilize the work enthusiasm of faculty and promote them make greater achievements in the appointed posts. [3]

\subsection{Improve Performance Appraisal}

The purpose of performance appraisal is to effectively promote the performance of individuals, and guide all teachers and their units to stride forward to the overall strategic objectives of the college. Performance appraisal should take the duties and tasks specified in the post appointment as standards to scientifically and reasonably evaluate the performance of faculty. The performance appraisal of teaching and research personnel should follow the discipline characteristics and research laws, as well as give play to teachers' personality and specialty. The evaluation of individual teachers by each department should fully consider the guiding role of personnel training, scientific research social services and cultural heritage. Through the assessment, we can stimulate the work initiative and enthusiasm of the staff, improve work efficiency and potential, and create a positive and harmonious atmosphere with unity and cooperation. The assessment should reflect the department's basic workload, complexity, the maintenance and growth of performance results, as well as the contribution to the college development, highlighting the characteristics and shinning points of the department.

\section{Summary}

The design and implementation of the incentive system for college teachers will inevitably encounter various problems. Basing on the actual situation of colleges and universities and combining the work characteristics of teachers and college's development goals to improve the system, we can make relevant systems really play a role in encouraging talents.

\section{References}

[1]. Song Hongzhen. Problems of the incentive mechanism for college teaching staff and countermeasures [J]. Education and Vocation. 2012 [26], p62-63.

[2]. Chen Xinxin. On the current incentive management for college teachers [J]. Journal of Yunmeng .2003, (24), p89-91.

[3]. Shi Yunlong. Research on China college teachers' incentive mechanism [J]. Continuing Education.2013, (11), p56-57. 